\title{
Segregação, infância generalizada e alegria: questões para a psicanálise
}

\section{Maria Claudia Formigoni}

Em 22 de outubro de 1967, em Paris, Lacan encerrou uma jornada sobre as psicoses da criança, organizada por Maud Mannoni. Convidado a falar sobre psicose, crianças e instituições de atendimento, ele foi muito além disso ${ }^{1}$.

Há cinquenta anos, Lacan já assinalara uma questão que, hoje em dia, muito nos concerne. Trata-se de uma "subversão sem precedentes" (LACAN, 1967/2003, p. 361) relacionada à estreita aliança entre discurso científico e capitalista, responsável pela universalização e homogeneização dos indivíduos. A incidência de tais discursos faz com que, na era do capitalismo, o sujeito barrado - aquele que é pura diferença, marcado por uma divisão e incompletude - fique de fora. Há uma tentativa de suturá-lo.

Isso não é sem consequências. Essa subversão inédita, também apontava Lacan em 1967, leva ao "problema mais intenso de nossa época, na medida em que ela foi a primeira a sentir o novo questionamento de todas as estruturas sociais pelo progresso da ciência" (Ibid., p. 360) e com o qual "teremos que lidar, e sempre de maneira mais premente" (Ibid): a segregação.

Podemos considerar que a segregação responde àquilo que há de sintomático na estrutura social. O sintomático da sociedade ataca e, como contra-ataque, surgem os efeitos de segregação. Mas o que seria esse sintomático da estrutura social?

A aliança estreita entre o discurso científico e o capitalista fez com que os indivíduos fossem reduzidos a objetos de saber. Quem sabe a respeito deles é um Outro que vocifera conhecimentos, palavras de ordem e respostas que, além de prometerem aniquilar as angústias e conquistar o almejado bem-estar, serviriam igualmente a todos. Trata-se de saberes totalizantes que encerram o sujeito em conjuntos fechados - a criança, o homossexual, o velho, o refugiado, a mulher... -deixando de fora sua singularidade.

Anulam-se as diferenças, apagam-se as subjetividades e instala-se uma - suposta - paridade. Junta-se, uniformiza-se e propõem-se aos sujeitos:

1 A fala por ele proferida está publicada em Outros escritos (2003) sob o título Alocução sobre as psicoses da criança (LACAN, 1967/2003, pp. 359-368). 
[...] ideais individuais que tendem a se reduzir a um plano de assimilação cada vez mais horizontal [...]. Numa civilização em que o ideal individualista foi alçado a um grau de afirmação até então desconhecido, os indivíduos descobrem-se tendendo para um estado em que pensam, sentem, fazem e amam exatamente as mesmas coisas nas mesmas horas, em porções do espaço estritamente equivalentes (LACAN, 1950/1998, p. 146).

O discurso que hoje nos domina vocifera a paridade e impõe o gozo como economia. Vende a ilusão de uma possível completude - via gadgets, falsos objetos $a$ produzidos pelo capitalismo - e de uma realização individual. Instaura, via consumo e produção, a insaciável falta a gozar. Exclui o ser-para-o-sexo e, consequentemente, o sujeito barrado.

Como afirma Colette Soler (2015b), a universalização trazida pela ciência vai bem com o individualismo promovido pelo capitalismo, que reduz cada um a não ser mais que um entre outros, sem distinção. As sociedades passam a ser compostas por massas humanas, isto é, agregados de unidades individuais em que a disparidade é eliminada e às quais se promete acesso ao objeto de gozo.

Quanto a essa especificidade da sociedade contemporânea, Lacan explica e questiona:

Os homens estão enveredando por uma época que chamamos planetária, na qual se informarão por algo que surge da destruição de uma antiga ordem social, que eu simbolizaria pelo Império, tal como sua sombra perfilou-se por muito tempo numa grande civilização, para ser substituída por algo bem diverso e que de modo algum tem o mesmo sentido - os imperialismos, cuja questão é a seguinte: como fazer para que massas humanas fadadas ao mesmo espaço, não apenas geográfico, mas também, ocasionalmente, familiar, se mantenham separadas? (LACAN, 1967/2003, pp. 360-361).

Sabemos que a entrada na linguagem é castradora e implica limite ao gozo. Aquele objeto suposto proporcionar a completude fica para sempre perdido, irrecuperável, permitindo justamente que se possa fazer laço. Nesse sentido, não há como ser cumprida a promessa feita pelo discurso capitalista no que se refere ao par complementar sujeito/objeto, à oferta da possibilidade de cada um estabelecer uma relação direta com determinado objeto, concretizando, de certa forma, a fantasia.

Conforme assinala Askofaré (2009b), todo sujeito é um excluído do gozo, é um exilado da relação sexual. A disparidade é, então, característica estrutural dos seres falantes. Não é algo contingente como veiculam ciência e capitalismo, mas algo essencial ao sujeito e imprescindível ao laço social, já que tem função de 
enlaçamento. Não se trata, portanto, de erradicar a exclusão, e sim de "acolher os 'excluídos' naquilo que eles têm de mais singular" (Ibid., p. 407).

A “subversão sem precedentes" - caracterizada pelo empuxo à paridade e por tentar deixar de fora a castração - afeta os laços sociais. Um ordenamento coletivo sustentado no laço opõe-se à paridade. O laço social tem como característica inerente instaurar o não todos iguais. Não é possível, portanto, fazer laço sem incluir a disparidade. Isso é o que permite dizer, portanto, que o capitalismo desfaz os laços sociais.

Quando esses se desfazem, resta somente a massa humana. Não há um ordenamento que deixa lugar para as verdades individuais e que permite viver juntos pela linguagem ao preço de uma disparidade de princípio. "Descobrimos que à medida que desaparecem as desigualdades significantes que fundam o laço social, a paridade crescente, idealizada [...] não reduz nem as violências nem as relações de força [...] simplesmente as desregula" (SOLER, 2015a, pp. 22-23). A segregação é, assim, consequência direta da degradação dos laços sociais.

Lacan, ainda em seu discurso de encerramento da jornada em Paris, anuncia que um dos sinais da entrada de um mundo inteiro no caminho da segregação é a "criança generalizada" (LACAN, 1967/2003, p. 367). Nessa formulação, complementada com a inusitada afirmação de que "não existe gente grande" (Ibid., p. 367), há uma alusão à paridade - todos crianças, todos iguais. Anula-se a distinção entre adultos e crianças, rompendo a disparidade inerente ao laço entre ambos.

Com a expressão "criança generalizada", Lacan, considerando o posicionamento estrutural da criança como objeto de gozo do Outro, também alude à posição de objeto em que o homem contemporâneo é colocado pelo discurso da ciência e do capitalismo. O ser humano é "reduzido a objeto da ciência e a corpo biológico [...] Lacan prevê como sintoma a indústria de comércio de órgãos que se desenvolveria, como de fato ocorreu" (PRATES PACHECO, 2012, p. 26).

Vivemos na era da infância generalizada, e a segregação surge como efeito. Efeito esse que é uma tentativa de dar tratamento à anulação das diferenças via separação espacial como forma de preservar lugares distintos. Contudo, a lógica que rege esse tratamento espacial se sustenta em um reconhecimento da diferença que, por concentrar e generalizar, favorece o surgimento de fenômenos como a misoginia, a dita criança tirana, o preconceito racial, entre outros. Eis aí, como alerta Prates Pacheco (Ibid., pp. 27-28), um ponto importante a ser considerado, pois diz respeito à segregação.

Etimologicamente, o verbo segregar deriva do latim segregare, que significa separar, apartar, afastar, isolar. O substantivo correspondente segregatio, onis, deu em português segregação. Assim, se há na segregação um 
isolamento, um afastamento, há por outro lado um reconhecimento da diferença que pode, entretanto, ser tomado como justificativa para uma valorização negativa, para o abuso do poder e a dominação, e para a discriminação no pior sentido.

Resta-nos, então, uma pergunta: o que podem, a psicanálise e os psicanalistas, diante de problemas tão cruciais?

Não há dúvidas de que não se deve ceder ao capitalismo e à ciência. É preciso, sim, subverter tais discursos para fazer valer a inexistência da relação sexual, o ser-para-o-sexo. O discurso analítico "pode suscitar um desejo outro, ou sustentar os desejos outros [...]. Sustentar um outro desejo é uma forma não de fazer barra somos todos presos ao discurso capitalista -, mas de subtrair alguma coisa desse discurso" (SOLER, 2011a, p. 65).

Psicanalistas que se debruçam sobre essa questão, como Askofaré (2009a), Soler (2011b) e Quinet (2009), apontam o amor como uma possível via para fazer frente à segregação e subtrair algo do discurso capitalista. No amor, a castração está em jogo. Servimo-nos dela e também a colocamos a serviço do outro. Além disso, o amor, por ser um limite ao narcisismo, permite aceitar as limitações impostas ao gozo. Sustentar os caminhos do amor via discurso analítico pode ser, portanto, uma forma de furar a ciência e o capitalismo, atenuando seus efeitos.

Além do discurso analítico e do amor - que pela transferência se dirige ao saber -, Lacan sinaliza aos analistas mais um modo de enfrentarmos, por meio de nossa prática e posicionamento, o mal-estar da civilização atual. Os indícios disso parecem estar em duas passagens de Alocução sobre as psicoses da criança (1967/2003). Transcrevo-as:

Mas estaremos nós à altura do que parecemos, pela subversão freudiana, ser convocados a carregar - o ser-para-o sexo? Não parecemos muito valentes para manter essa posição. Nem tampouco muito alegres (Ibid., pp. 362-363).

[...] por que, provavelmente, Freud sentiu que era seu dever reintroduzir sua medida na ética através do gozo? E acaso não é tentar agir com vocês como com aqueles de quem essa é a lei, desde então, vou deixá-los com esta pergunta: que alegria encontramos nós naquilo que constitui nosso trabalho? (Ibid., p.367).

Lacan, nesses questionamentos, faz referência a algo muito importante: o gozo como medida ética. Vimos que o capitalismo se opõe a isso. Por prometer a restituição de uma condição essencial aos sujeitos, promove a suposta existência de 
um gozo que seria ilimitado. Assim, o mais-de-gozar, a falta a gozar, torna-se causa geral do desejo e motor que anima a economia subjetiva - e não só essa. $\mathrm{O}$ capitalismo veicula também a ideia de que os gozos são iguais e podem ser distribuídos de forma equivalente.

A causa analítica, por sua vez, como diz Quinet (2009, pp. 36-37), "não apregoa a justiça distributiva do gozo, pois este não pode ser repartido [...] O gozo distribuído equitativamente levaria cada um ao direito de gozar sobre o outro - o gozo para todos - [...] com a abolição do particular de cada um”. As consequências dessa abolição sabemos bem quais são. Por isso, é fundamental ter o gozo como ética e sustentar a castração como forma de permitir que cada um responda, singularmente, à inexistência da relação sexual.

Essa questão é, sem dúvida, fundamental. Contudo, quero destacar algo mais que Lacan assinala nesses trechos transcritos e que, para mim, também deve marcar a tarefa do analista e é efeito da incidência do próprio discurso analítico. Trata-se da alegria.

Mas por que, afinal, seria válido pensar que a alegria pode ajudar os analistas na sua tarefa de sustentar o ser-para-o-sexo e, assim, buscar fazer frente aos efeitos danosos da ciência e do capitalismo? Formulemos os primeiros passos de uma tentativa de resposta a esse questionamento.

Lacan (1967/2003, p. 361), baseando-se em Dante, diz que a tristeza é o maior dos pecados. Refere ser alegre e se divertir com aquilo que faz. A tristeza, em suas palavras, "não é um estado de espírito, é simplesmente uma falha moral, [...] um pecado, o que significa, uma covardia moral, que só é situado, em última instância, a partir [...] do dever de bem dizer, ou de se referenciar no inconsciente" (LACAN, 1973/2003, p. 524). Considera a tristeza índice de uma relação frouxa com o desejo e sinal do imperativo de gozo.

Do lado oposto à tristeza, Lacan situa o gaio saber ( gay sçavoir). De modo resumido, podemos dizer que esse saber tem seu fundamento na falta estrutural chamada desejo e é considerado uma virtude. Trata-se de uma virtude ética, pois consiste "não em compreender, fisgar [piquer] no sentido, mas em roçá-lo tão de perto quanto se possa, sem que ele sirva de cola para essa virtude, para isso gozar com o deciframento, o que implica que o gaio issaber, no final, faça dele apenas a queda” (Ibid., p. 525).

Tal virtude seria uma maneira de reinscrever o desejo, de dar lugar ao singular, modificando a posição de exclusão e de dejeto sustentada pela ciência e pelo capitalismo - e também pela fantasia neurótica. Aposta-se que, com isso, a particularidade de gozo seja acolhida e que os sujeitos possam ser contados um a um, descolando-se das vociferações homogeneizantes advindas dos discursos que dominam nossa época.

Como afirma Soler (2011b), tristeza e gaio saber são dois afetos que se referem à relação com o saber inconsciente, conforme esse seja recusado ou, ao contrário, decifrado palavra a palavra. Aquele que "tenha a valentia de se deixar enganar [se 
faire dupe] por suas letras ou seus signos a fim de tolerar o sentido sempre fugidio ao em vez de se satisfazer com ele" (Ibid., p. 71) pode experimentar o júbilo proporcionado pela queda da alienação do sujeito ao significante do Outro.

A alegria do saber é consequência da passagem do não sentido ao não sentido gozado, um gozo sentido no corpo. Essa passagem é essencial, porque produz um ganho sobre o sintoma ao preservar uma parte de real - índice da disparidade fundamental - que não se deixa encobrir pelos imperativos veiculados. Assim, fica mais claro porque é o discurso do analista e, por que não, também a alegria, que podem subverter o discurso capitalista.

Pessoa (2012) nos lembra que a passagem do não sentido ao não sentido gozado é uma vitória do real e que, por isso, causa desordem. Assinala que "experimentar alegria nessa vitória é uma questão de opção. Uma opção do psicanalista, estritamente relativa ao seu discurso, pois, nos outros, essa desordem é coisa a se evitar a qualquer preço”.

Optar pela alegria permitiria, portanto, ser criança de outro modo que não aquele imposto pelo capitalismo. Ser alegre marca a passagem da criança enquanto sendo gozada, objeto de gozo do Outro - todos enquanto objetos de gozo da ciência - para uma posição de poder gozar disso. Optemos, então, por freude ${ }^{2}$ como fez Lacan. Trabalhemos com (a) alegria!

\section{Referências bibliográficas}

ASKOFARÉ, S. (2009a) Aspectos da segregação. A Peste: Revista de Psicanálise e Sociedade, v.1, n. 2, jul./dez., 2009, pp. 345-354. . (2009b) O jogo da exclusão. A Peste: Revista de Psicanálise e Sociedade, v.1, n. 2, jul./dez., 2009, pp. 401-407.

LACAN, J. (1950) Introdução teórica às funções da psicanálise em criminologia. In: Escritos, Rio de Janeiro: Jorge Zahar Ed., 1998.

(1967) Alocuções sobre as psicoses da criança. In: Outros escritos. Rio de Janeiro: Jorge Zahar Ed., 2003.

. (1973) Televisão. In: Outros Escritos. Rio de Janeiro: Jorge Zahar Ed., 2003.

PESSOA, S. (2012) O riso: expressão de um saber, uma vitória do real. Disponível em: https://lacaneando.com.br/o-riso-expressao-de-um-saber-uma-vitoria-do-real/. Acesso em: 10 maio 2016.

PRATES PACHECO, A. L. (2012) Infância e autismo: entre a segregação e a concentração. A Peste: Revista de Psicanálise e Sociedade, v.4, n. 1 e 2, jan./jun./ jul./dez. 2012, pp. 23-32.

2 Em alemão, "alegria". 
QUINET, A. A estranheza da psicanálise. Rio de Janeiro: Jorge Zahar Ed., 2009.

SOLER, C. (2011a) O discurso capitalista. Stylus: Revista de Psicanálise, n. 22, mai. 2011, Rio de Janeiro, pp. 55-68.

. (2011b) Los afectos lacanianos. Buenos Aires: Letra Viva, 2011.

. (2015a) Lo que queda de la infancia. Buenos Aires: Letra Viva, 2015.

. (2015b) ¿Qué es lo que hace lazo? Medellín: Asociación Foro del Cam-

po Lacaniano de Medellín, 2015.

\title{
Segregação, infância generalizada e alegria: questões para a psicanálise Segregation, generalized childhood and joy: questions for psychoanalysis
}

\begin{abstract}
resumo
Há cinquenta anos, Lacan já assinalava uma questão que ainda hoje nos concerne. Trata-se de uma "subversão sem precedentes" relacionada à estreita aliança entre o discurso científico e o capitalista, responsável pela universalização e homogeneização dos indivíduos. Isso teria como efeito a infância generalizada, que, segundo Lacan, assinala a entrada do mundo na era da segregação. Mas por quê? Qual a relação entre infância generalizada e segregação? Como pensar a posição do analista diante desses efeitos danosos do discurso capitalista? E a alegria, como se relaciona a essas questões? A autora considera estas questões cruciais para a psicanálise.
\end{abstract}

\section{palavras-chave:}

Lacan; discurso do capitalista; segregação; infância generalizada; alegria.

\section{abstract}

Fifty years ago, Lacan was already pointing out an issue that still concerns us today. It is an "unprecedented subversion" related to the close alliance between scientific and capitalist discourse responsible for the universalization and homogenization of the individuals. This would have, as effect, the general childhood, which, according to Lacan, marks the entrance of the world into the segregation era. But why? What is the relationship between generalized childhood and segregation? How can we think of the analyst's position upon these damaging effects of capitalist discourse? How does joy relate to that? The author considers these issues crucial to psychoanalysis.

\section{keywords:}

Lacan; capitalist discourse; segregation; generalized childhood; joy. 
FORMIGONI, Maria Claudia

Recebido:

24/05/2017

Aprovado:

$12 / 06 / 2017$ 